Revista de

Contabilidade e

Organizações

www.rco.usp.br
DOI: http://dx.doi.org/10.11606/rco.v9i25.55522
Journal of

Accounting and

Organizations

\title{
Gestão pública no Brasil: uma proposta de mensuração da educação fiscal do cidadão
}

Erivan Ferreira Borges ${ }^{\mathrm{a}}$; Jose Matias Pereira ${ }^{\mathrm{b}}$; Gilmara Mendes da Costa Borges ${ }^{\mathrm{a}}$

${ }^{a}$ Universidade Federal do Rio Grande do Norte

${ }^{b}$ Universidade de Brasilia

\section{Informações do Artigo}

Histórico do Artigo

Recebido: 10 de maio de 2013

Aceito: 24 de novembro de 2015

\section{Palavras-chave:}

Educação fiscal.

Programa Nacional de

Educação Fiscal (PNEF).

Cidadania.

Gestão Pública.

Análise Fatorial.

\begin{abstract}
Resumo
Neste artigo propõe-se mensurar o nível de educação fiscal do cidadão, a partir da base de dados do Programa Nacional de Educação Fiscal - PNEF. São apresentados trabalhos que tratam da educação fiscal em nível nacional e internacional, cujos fundamentos retratam uma educação voltada ao exercício da plena cidadania. Os dados utilizados são resultados de uma pesquisa de campo realizada com o apoio da Escola de Administração Fazendária, utilizando como instrumento de coleta o Survey Monkey. A amostra compreendeu 1.804 respostas a um questionário estruturado a partir dos fundamentos da educação fiscal pregados pela gestora do programa (ESAF). Os dados foram tratados por análise fatorial, sob o pressuposto de identificar dimensões latentes do nível de educação fiscal dos cidadãos. Comprovouse a possibilidade de mensuração do nível de entendimento da educação fiscal por múltiplos componentes, pressupondo ainda uma contribuição ao estado da arte da pesquisa sobre educação fiscal e abrindo campo para estudos que objetivem revalidar os achados.
\end{abstract}

Copyright (C) 2015 FEA-RP/USP. Todos os direitos reservados

\section{INTRODUÇÃO}

A educação fiscal contribui para a formação da consciência do cidadão orientando-o para princípios que norteiam a construção de um sistema tributário que visa à distribuição de renda mais igualitariamente (ESAF, 2009). Borges et al (2008) delimitam que o conhecimento dos fundamentos que identificam a educação fiscal pode proporcionar ao governo o redimensionamento de suas políticas de inserção social. Esse redimensionamento deve partir da formulação e da implantação de políticas, programas e projetos que favoreçam e disseminem o pleno entendimento do que é o Estado, como ele funciona e atua, suas obrigações em gerenciar adequadamente os recursos que arrecada, e de dar a publicidade necessária dos seus atos à sociedade. Também devem permitir o entendimento sobre a efetiva participação nesse processo, conscientizando a sociedade sobre a importância da contribuição progressiva com tributos, e por adequada formação para fiscalizar a atuação do Estado.

Para a ESAF, o Programa Nacional de Educação Fiscal - PNEF sintetiza, através dos seus objetivos e diretrizes, os princípios de ética e cidadania na área fiscal. É uma experiência de participação, controle social e aprofundamento democrático. Esses aspectos são entendidos pela gestora como os fundamentos do programa, e são repassados à sociedade com o objetivo de possibilitar a compreensão das administrações financeira, patrimonial e orçamentária do Estado (CARTAXO, 2004; ESAF/MF/MEC, 2009).

Esses argumentos revestem a educação fiscal como um conjunto de conhecimentos e atitudes que pode influenciar a vida das pessoas, e portanto, provocar mudança social. Medir esse conhecimento, presume-se, evidencia o quanto o cidadão é ou seria capaz de provocar mudanças. Sob esse argumento, e por não se observar na literatura tentativas de mensurar esse conhecimento, define-se assim o problema central desta pesquisa: Os elementos que fundamentam a educação fiscal do cidadão permitem mensurá-la em forma de indicador multidimensional?

Autor Correspondente: Tel (84) 3421-4950

E-mail: Erivanfborges@gmail.com (E. F. Borges); Matiaspereira51@gmail.com (J.M. Pereira); Gilmaramcb@gmail.com (G.M.C. Borges);

Universidade Federal do Rio Grande do Norte - Centro de Ciências Sociais Aplicadas, Departamento de Ciências Contábeis - Av. Senador Salgado Filho - Lagoa Nova - 59000-000 - Natal - RN, Brasil 
Para alcançar resposta ao problema, busca-se identificar inicialmente os fundamentos que caracterizam a educação fiscal dos indivíduos e em seguida, a partir desses fundamentos, construir e validar um indicador de mensuração da educação fiscal, buscando estabelecer uma escala de medição do nível de formação educacional fiscal dos cidadãos. Os achados dos trabalhos são utilizados para fundamentar uma pesquisa (Borges, 2012) que relaciona o nível de educação fiscal do cidadão a gestão eficiente de recursos públicos pelos municípios brasileiros Verifica-se na presente pesquisa limitações inerentes a sua consumação, como a composição do instrumento de pesquisa, por considerar dimensões específicas, e o próprio comprometimento do pesquisado.

\section{FUNDAMENTAÇÃO TEÓRICA}

No Brasil, conforme dispõe o artigo $3^{\circ}$ da Constituição Federal, incisos I e II, são objetivos fundamentais do Estado construir uma sociedade livre, justa e solidária, garantir o desenvolvimento nacional, erradicando a pobreza e a marginalização, e reduzir as desigualdades sociais e regionais. Para Freire (2005), o primeiro passo na busca e alcance desses objetivos é educar o cidadão.

O processo educativo abrange as mais diversas áreas do conhecimento, e faz parte da evolução humana, tornando-a capaz de conviver em sociedade. Essa capacidade de socialização pode ser entendida como elementos que fundamentam o que se conhece como cidadania e democracia, estágios da evolução que exige um acúmulo de valores e consciências, sobre o que é melhor para todos. Isso significa que o processo de conscientização social, inclusive tributário, não é fruto do acaso, mas resultado de um conjunto de ações coordenadas resultantes do processo educativo por que passa o homem (SAINZ DE BUJANDA, 1967; LOBO et al, 2005; FREIRE, 2005).

Sainz de Bujanda (1967) afirma que a educação tributária deve ser objeto de um ramo importante da ciência pedagógica, pressuposto que leva o teórico espanhol a propor a Teoria da La Educación Tributária, em cujos fundamentos o trabalho se apoia. Para o autor, a educação fiscal é resultado de uma formação sistêmica, voltada à conscientização do contribuinte sobre o papel social do tributo. Na sua formulação, considera que a educação fiscal está e deve estar inserida no contexto geral da educação, dentro da ciência da Pedagogia, uma vez que deve se preocupar com os problemas da sociedade e suas possíveis soluções. Sustenta ainda que a educação fiscal não deve se restringir a uma disciplina, pois sua efetividade é resultado de um processo global, que envolve todo o conhecimento que permeia a formação da personalidade do indivíduo. Qualquer tipo de abordagem sobre o tema que não se apoie em uma consideração geral da personalidade do contribuinte será unilateral e insuficiente (SAINZ DE BUJANDA, 1967).

Para o autor, entre as operações lógicas que conduzem o conceito de educação fiscal, está o entendimento dessa educação dentro do contexto educativo geral e da análise científica dos elementos que conduzem o comportamento do contribuinte. Além de apresentar o conceito, o autor faz um apanhado quanto aos ideais da educação fiscal, seus métodos de abordagem e os resultados que esse processo traz em termos sociais. Os ideais se fundamentam na determinação de conteúdos educativos concretos e no repertório de ações que integram o comportamento do contribuinte educado, a fim de que este cumpra suas obrigações e deveres, e ao mesmo tempo fiscalize a ação estatal no âmbito tributário. Para alcançar esses ideais, o autor ressalta que é importante fortalecer o sentido ou sentimento de responsabilidade moral, dentro de uma abordagem psicológica sobre a importância do tributo para a sociedade, mas sem se deixar levar pelo perigo do psicologismo fiscal.

\subsection{Perspectivas da educação fiscal no Brasil e no mundo}

As experiências internacionais relacionadas à discussão da educação fiscal têm recebido grande atenção dos pesquisadores latinos, a maioria ligada ao Instituto de Estudos Fiscais Espanhol (Fernandez; Ruiz, 2002; Lobo et al, 2005; Yubero; Lobo; Garcia, 2008; Garcia, 2009; Yubero et al, 2009). As análises, com prevalência dos aspectos institucionais e teóricos, concentram-se nas bases do programa de educação fiscal da União Europeia e o do programa de educação cívico tributário da Espanha.

O que se percebe na análise desses estudos é a preocupação em estabelecer diretrizes conjuntas de atuação entre os sistemas educacionais e tributários de cada país através dos órgãos de governo responsáveis pelas áreas, tendo como pressuposto imediato que a conscientização e a consequente atuação cidadã em termos tributários começa a partir da educação global do indivíduo, e devem estar presentes na sua vida desde a formação básica. 
Essas preocupações estão presentes em outros estudos (DIAZ; GARCIA, 1999; CISNE; MENEZES, 2001; BOTANA, 2006; CORRALES; GARCÍA, 2007; NEVES, 2008; MUÑOZ, 2007; LIMA, 2008; TAPIA, GAONA; TUMBACO, 2009;; ESTEVEZ, 2010; GARCÍA, BEYAERT; PABLOS, 2010; ESPER, 2010; KINNEY, 2010; KENNA, 2011; INSTITUTO DE ESTUDIOS FISCALES - ÁREA DE SOCIOLOGÍA TRIBUTARIA, 2001, 2008; GIARRIZZO; SIVORI, 2010; KENNA, 211; ZEA, 2011; GARCÍA; ESCOBAR, 2011) que tratam desse e de outros assuntos transversais ao tema, mas com focos diferentes ao objetivos deste trabalho.

Analisando-se a produção acadêmica sobre educação fiscal no Brasil, percebe-se que esta ainda pode ser considerada incipiente, conforme apontam Grzybovski e Hahn (2006). Não se verificam, nos trabalhos existentes, investigações em uma perspectiva pedagógica, dentro da filosofia da educação, como avaliação de programa de governo, ou em uma perspectiva de mensuração, como variável capaz de influenciar a eficiência pública.

Existe uma vasta literatura sobre os temas transversais que fundamentam o programa (controle social, accountability, justiça fiscal, cidadania), mas nada que qualifique essa associação de conceitos como um corpo coordenado que represente a base subjacente de uma efetiva educação fiscal. Destacam-se os trabalhos de Pertuzatti e Merlo (2005), Pereira (2005), Sholz (2005), Grzybovski e Hahn (2006) e Borges et al. (2008), que trazem perspectivas diferentes quanto à abordagem do tema, sem considerar os objetivos traçados para esta pesquisa.

\subsection{O Programa Nacional de Educação Fiscal (PNEF) e seus fundamentos}

Educar é cumprir uma exigência constitucional e não envolve apenas aspectos de ordem geral, mas, um processo de conscientização tributária que permita ao indivíduo e ao Estado conhecerem e entenderem como devem ser tratados os impostos e as contribuições de forma a promover a igualdade social (SAINZ DE BUJANDA, 1967; LOBO et al, 2005; SHOLZ, 2005; YUBERO et al, 2009).

O Programa Nacional de Educação Fiscal (PNEF) foi desenvolvido para promover e institucionalizar a educação fiscal para o pleno exercício da cidadania, uma vez que para seus articuladores é um trabalho de sensibilização da sociedade para o entendimento sobre a função socioeconômica do tributo (ESAF, 2009). Em sua cartilha $\mathrm{n}^{\circ} 1$, o PNEF delimita que a educação fiscal pode ser entendida como uma nova prática educacional que tem como objetivo o desenvolvimento de valores e atitudes, competências e habilidades necessárias ao exercício de direitos e deveres na relação recíproca entre o cidadão e o Estado. Fundamenta-se na (a) conscientização da sociedade sobre a estrutura e o funcionamento da Administração Pública; (b) na função socioeconômica dos tributos; (c) na aplicação dos recursos públicos; (d) nas estratégias e nos meios para o exercício do controle democrático (ESAF/MF/MEC, cad. 1, 2009). Dessa forma, minimiza-se o conflito na relação entre o cidadãocontribuinte e o Estado arrecadador, que tem a função primeira de conscientizar.

Por essas características, a educação fiscal não é um programa sem projeto ou metodologia. Obedece a determinados fundamentos, entendidos como condicionantes a uma adequada educação fiscal, considerando: a) a compreensão pelo cidadão do papel do Estado, seus mecanismos de financiamento e o desempenho das funções públicas; b) o entendimento da função sócioeconômica do tributo e dos procedimentos fiscais de combate às desigualdades sociais; c) a promoção da justiça fiscal e da ética distributiva; d) a relação harmoniosa e cooperativa entre o cidadão e o Estado; e) o controle social da boa aplicação dos recursos públicos, com vistas à eficiência e à qualidade do gasto; f) o combate às práticas nocivas na gestão pública, tais como corrupção, malversação de recursos, sonegação, e competição fiscal predatória; g) a disseminação das boas práticas de gestão pública, transparência, ética fiscal, cumprimento voluntário, atenção ao contribuinte/cidadão e justiça fiscal; h) a restauração da legitimidade do papel do Estado, pela compreensão e interpretação adequada das suas leis e atos moralmente condicionados.

De certa forma, esses fundamentos consolidam o texto constitucional brasileiro e materializam o objetivo deste de servir como instrumento capaz de assegurar o exercício dos direitos sociais e individuais, a liberdade, a segurança, o bem-estar, o desenvolvimento, a igualdade e a justiça como valores supremos de uma sociedade fraterna, pluralista e sem preconceitos, fundada na harmonia social e comprometida, na ordem interna e internacional.

O PNEF, portanto, objetiva formar um cidadão consciente de sua responsabilidade como contribuinte, permitindo-o tornar-se mais eficiente no seu papel de fiscalizador das ações desempenhadas pelos setores públicos. Propõe-se ainda servir como um instrumento de combate face à corrupção, à sonegação e ao desperdício público. 


\subsection{Desafios e dificuldades de consolidação das bases do PNEF}

As diretrizes estratégicas do PNEF apontam como um dos problemas mais graves na disseminação, difusão e institucionalização do PNEF, a falta do estabelecimento de um referencial teórico metodológico que fundamente os eixos temáticos, o material didático e as ações e atividades do programa (ESAF/MF/MEC, 2009). Essa condição pode ser associada à falta de pesquisas nacionais sobre o tema. Para Grzybovski e Hahn (2006) uma das saídas para resolver esse descompasso é a implantação de programas de educação fiscal.

É em face a essa realidade que a educação fiscal se apresenta como uma forma de solucionar parte dos problemas sociais e possibilitar a participação do cidadão na redução das desigualdades. Consiste em um dos pilares do processo educacional, uma vez que no mundo contemporâneo nenhum país supera as desigualdades sociais sem focalizar a educação como prioridade. Ela contribui para a formação da consciência do cidadão, orientando-o para princípios que norteiam a construção de um sistema tributário que visa à distribuição igualitária de renda.

Para a construção de uma sociedade igualitária, na perspectiva como se apresenta o fundamento pedagógico da educação fiscal, é condição singular a gestão pública participativa. A participação crescente dos cidadãos a quem cabe acompanhar e controlador as ações dos governantes - contribui para elevar a transparência e os resultados das políticas e programas direcionados para gerar o bem comum da população, em especial, promover a inclusão social, e dessa maneira, alcançar uma maior eficiência das atividades e ações governamentais.

O comportamento fiscal correto é um sintoma, e também uma consequência, de uma sólida consciência cívica. "A consciência cívico-fiscal não é algo natural: é um produto social e, portanto, resultado da educação" (LOBO et al, 2005, p. 8). Esse pressuposto conduz ao entendimento de que a educação fiscal não deve se limitar a uma mera exposição da sua importância para a sociedade democrática, mas antes constituir-se em uma efetiva educação moral, e cidadania responsável (SAINZ DE BUNJANDA, 1967; LOBO et al, 2005). Seu objetivo principal deve concentrar-se na transmissão de ideias, valores e atitudes favoráveis à responsabilidade fiscal e contrários às práticas de condutas fraudulentas.

Essas diretrizes são aderentes aos pressupostos apontados pela ESAF como fundamentos da educação fiscal no Brasil, que também objetivam proporcionar à sociedade uma clara definição do que representa uma consciência fiscal, resultado de um processo lógico/racional, sobre a necessidade de se ter uma fonte social de financiamento das necessidades públicas e comuns. Esse processo é dinâmico e o principal critério observado é a cidadania, que implica em cada um assumir suas responsabilidades sociais como uma contrapartida necessária aos direitos civis (LOBO et al, 2005; BUFFON, 2009).

\section{METODOLOGIA DA PESQUISA}

A pesquisa é caracterizada como exploratória-descritiva e objetivou proporcionar ao pesquisador um maior envolvimento com o problema, esclarecendo conceitos, e o consequente aprimoramento de ideias e descobertas sobre o assunto, resultando em uma melhor sistematização para a segunda etapa (descritiva) (GIL, 2006; MARCONI e LAKATOS, 2007).

A população e a amostra são determinadas a partir do conjunto de respostas ao instrumento de pesquisa, enviado pelo critério de acessibilidade a base de e-mails do pesquisador, da sua rede de contatos, e da base de dados da ESAF, composta por todos os indivíduos que realizaram o curso de disseminador da educação fiscal.

O trabalho é operacionalizado por um indicador, definido a partir de um modelo conceitual estabelecido, considerando os fundamentos e pressupostos da educação fiscal. A ferramenta estatística utilizada é a análise fatorial, que permite identificar dimensões com dados semelhantes a partir de um conjunto de dados (HAIR et al., 2005). Todos os pressupostos assumidos objetivam simplificar a verificação das hipóteses estabelecidas para o trabalho.

\subsection{Definição da fundamentação das variáveis que suportam a mensuração da educação fiscal}


Para a mensuração e coleta dos dados sobre o nível de educação fiscal do cidadão elaborou-se um instrumento a partir das bases apontadas pelo PNEF: a) Dimensão da Compreensão do Papel do Estado (IComp); b) Dimensão do entendimento sobre a Função socioeconômica do tributo (ISocEcon); c) Dimensão sobre o entendimento da Promoção da Justiça Fiscal e da Ética Distributiva (IJusEti); d) Dimensão da Relação do entendimento sobre a necessidade de manter uma relação harmoniosa entre o Cidadão e o Estado (IRel); e) Dimensão sobre o entendimento de Controle Social (IConSoc); f) Dimensão do entendimento sobre a necessidade de Combater a Corrupção (IComCor); e, g) Dimensão do entendimento das Boas Práticas de Gestão Pública (IPratGP).

Para cada dimensão foi instrumentalizado um conjunto de variáveis que melhor se adequaram aos testes. Para instrumento final, foram definidas cinco variáveis para cada dimensão, medidas através de uma escala Likert de 10 pontos (variando de acordo com o grau de importância atribuído a cada variável, de 1 - menor - a 10 - maior).

As bases para formulação das variáveis foram extraídas da interpretação dos fundamentos presentes nos cadernos elaborados pela ESAF. Os cadernos sinteticamente especificam quais são as diretrizes do programa, seus objetivos e abrangência, no contexto da educação fiscal e da educação pública (caderno 1); discutem a relação entre o estado e a sociedade, suscitando temas quanto à organização da vida em sociedade e suas implicações na garantia do estado democrático de direito e da cidadania (caderno 2); delimitam qual é a função social dos tributos, destacando a importância destes na atividade financeira do estado para a manutenção das políticas públicas e melhoria das condições no contexto de vida (Caderno 3); e apresentam o que vem a ser a gestão democrática dos recursos públicos, discutindo temas ligados ao orçamento, o compromisso social e fiscal do gestor público e sobre o exercício do controle social (caderno 4). Esses fundamentos são apresentados nos artigos $1^{\circ}$ e $3^{\circ}$ da Constituição Federal, combinados com os art. $5^{\circ}$ (direitos e deveres individuais e coletivos), $6^{\circ}$ e $7^{\circ}$ (direitos sociais) e artigos $194^{\circ}$ a $232^{\circ}$ (ordem social) (ESAF, 2009) e materializam o aspecto de cidadania que deve estar na estrutura dos estados democráticos.

Tratando sobre tributação e dignidade humana, Estevez e Esper (2009) e Buffon (2009) consideram que não há fórmula viável nem caminhos factíveis se a ideia de cidadania se restringe ao sentimento de "direito a ter direitos", pois é preciso que cada um contribua com sua parcela de esforços. Assim, o efetivo conhecimento dos direitos e garantias sociais engloba o entendimento proporcional dos deveres, que incluem o relativo ao pagamento de tributos, sendo um dos principais dentro de um Estado Social (BUFFON, 2009). Para facilitar o entendimento, alguns desses argumentos, traduzidos em princípios, são adotados pela ESAF (2009, p. 19-21) para fundamentar o PNEF, que em essência são conceituados como:

- $\quad$ Princípio da legalidade (CF, art. 150, I): tem a finalidade garantir os direitos e os deveres individuais e coletivos, pois, nos Estados democráticos, não apenas os indivíduos são subordinados à lei, mas também a própria administração pública. Nesse sentido, a legalidade, como princípio fundamental do Estado de Direito, não se restringe a vedar ou proibir a tributação sem lei, mas, fundamentalmente garantir, a todo cidadão, seguranças jurídica, econômica e social;

- Princípio da anterioridade da lei (CF, art. $150^{\circ}, \mathrm{III}, \mathrm{b}$ e c): esse princípio proíbe a exigência de tributo ou seu aumento no mesmo exercício em que tenha sido publicada a lei que o instituiu, a fim de evitar que o contribuinte seja surpreendido pela majoração da carga tributária (É um corolário do princípio da não surpresa);

- Princípio de irretroatividade da lei $\left(\mathrm{CF}\right.$, art. $150^{\circ}$, III, a): esse princípio é também um princípio geral de Direito. Visa a impedir que determinada lei produza efeitos sobre fatos ocorridos antes de sua vigência. A lei não deve retroagir, a menos que seja benigna ao contribuinte;

- Princípio da isonomia (caput do art. $5^{\circ}$ da CF): trata-se da igualdade de todos perante a lei. Esse princípio aparece na Constituição Federal como um dos cinco direitos fundamentais;

- Princípio da uniformidade da tributação $\left(\mathrm{CF}\right.$, art. $\left.151^{\circ}, \mathrm{I}\right)$ : “É vedado a União instituir tributo que não seja uniforme em todo o território nacional ou que implique distinção ou preferência em relação a Estado, ao Distrito Federal ou a Município”. No entanto, a Constituição permite que a União exerça uma política de incentivos fiscais para promover o equilíbrio entre as diversas regiões do país;

- Princípio da capacidade contributiva $\left(\mathrm{CF}\right.$, art. $\left.145, \S 1^{\circ}\right)$ : busca a justiça fiscal e social, pressupondo a exigência maior a quem tem mais condição econômica e isentando ou reduzindo a incidência tributária para os contribuintes com menor capacidade econômica (contribuir de acordo com sua capacidade). Esse princípio atende ao imperativo da redistribuição de renda. Em respeito ao princípio, a legislação tributária deve aplicar alíquotas diferenciadas e efetuar redução parcial ou total da base de cálculo, objetivando conformar o tributo o mais próximo possível da real capacidade de pagamento de cada contribuinte; 
- Princípio do não confisco (CF, art. 150, IV): busca proteger o contribuinte contra a possibilidade de o Estado instituir leis e atos que tomem totalmente o seu patrimônio ou a renda do contribuinte. A análise de cada caso permite dizer se há ou não confisco, uma vez que tributos com características diferentes comportam parâmetros diferentes.

Além desses aspectos, a teoria pressupõe que: (i) a educação fiscal é resultado de uma formação sistêmica, voltada a conscientização do contribuinte sobre o papel social do tributo; (ii) está e deve estar inserida no contexto geral da educação e na análise científica dos elementos que conduzem o comportamento do contribuinte; (iii) pode ajudar a consolidar a justiça e a racionalidade do sistema tributário, e a simplificar a administração financeira do Estado, dando um novo sentido ao processo tributário; e (iv) O comportamento fiscal correto é um sintoma, e também uma consequência, de uma sólida consciência cívica, que é um produto social resultante da educação(SAINZ DE BUNJANDA, 1967; LOBO et al, 2005).

A partir desses fundamentos, o pressuposto assumido é de que existem elementos que permitem mensurar o nível de entendimento do cidadão sobre a disseminação das boas práticas de gestão pública, transparência, ética fiscal, cumprimento voluntário, atenção ao contribuinte/cidadão e justiça fiscal.

\subsection{Coleta dos dados}

A coleta dos dados foi realizada por meio eletrônico, a partir do sítio específico para esse tipo de pesquisa (www.surveymonkey.com.br). O Survey Monkey possibilita controlar o total de participantes na pesquisa pelo número do Internet Protocol - IP, de maneira que não há a possibilidade de dupla participação a partir de um mesmo equipamento utilizado para responder à pesquisa. Foram enviados aproximadamente 80 (oitenta) mil e-mails, replicando-se o envio em outras três oportunidades, entre os dias 21 de junho e 10 de agosto de 2011, obtendo-se ao final 2.806 questionários respondidos.

\section{TRATAMENTO E ANÁLISE DOS DADOS}

Entre as características da amostra, observa-se que 47,3\% dos pesquisados são do gênero masculino e $52,7 \%$ do gênero feminino; a grande maioria dos respondentes, 55,5\%, têm entre 21 e 50 anos, destacando-se que $26,3 \%$ têm entre 21 e 30 anos, e $28,2 \%$ têm entre 41 e 50 anos; a maioria dos pesquisados (49,4\%) é de funcionários públicos; e a maioria dos pesquisados tem curso superior $(86,80 \%)$, sendo que $55,5 \%$ destes têm pósgraduação em níveis de especialização, mestrado ou doutorado.

\subsection{Dimensões do indicador do nível educação fiscal}

Dado o caráter exploratório do estudo, optou-se inicialmente por mensurar as dimensões da educação fiscal pela aplicação da média aritmética ponderada. Essa metodologia é aplicada na avaliação do grau de conhecimento em todos os níveis acadêmicos, como no trabalho de Montovani e Viana (2008). Esses autores utilizaram essa metodologia associada à posterior validação do índice de confiabilidade do instrumento pelo Alfa de Cronbach.

O Alfa de Cronbach estima quão uniformemente os itens contribuem para a soma não ponderada do instrumento, variando em uma escala de 0 a 1 (MAROCO; MARQUES, 2006). Essa propriedade é conhecida como consistência interna da escala, que permite interpretar o índice como o coeficiente médio de todas as estimativas de consistência interna que seriam obtidas se todas as divisões possíveis da escala fossem feitas $(\mathrm{CRONBACH}$, 1951; MAROCO; MARQUES, 2006).

Nunnally (1978) Devellis (1991) consideram que um instrumento ou um teste podem ser classificados com boa confiabilidade se o índice for igual ou superior a 0,70 . Porém, salientam que em ciências sociais, um $\alpha$ de 0,60 pode ser considerado aceitável, desde que os resultados obtidos com o instrumento sejam interpretados com precaução e tenham em conta o contexto de computação do índice. Nessa perspectiva, foram realizados os cálculos do indicador, tanto para a composição total do instrumento, como para suas dimensões. $\mathrm{O}$ valor obtido para a composição total do instrumento (35 itens) foi de 0,963. Por sua vez, a Tabela 1 apresenta os valores obtidos 
para as dimensões:

Tabela 1. Estatística Alpha de Cronbach - Dimensões

\begin{tabular}{clcc}
\hline Descrição das Dimensões & Alpha & No. Itens \\
& IComp &, 889 & 5 \\
& ISocEcon &, 830 & 5 \\
\multirow{6}{*}{ Dimensão } & IJusEti &, 813 & 5 \\
& IRel &, 955 & 5 \\
& IConSoc &, 943 & 5 \\
& IComCor &, 902 & 5 \\
& IPratGP &, 876 & 5 \\
\hline
\end{tabular}

Fonte: Dados da pesquisa

Comparando os resultados para o instrumento completo, assim como suas dimensões, percebe-se que os níveis de $\alpha$ alcançados estão dentro das faixas apontadas pelos autores. Essa condição evidencia que de forma geral, e em cada dimensão proposta, o instrumento consegue captar o que se propõe, com altos índices de confiabilidade.

\subsection{Análise fatorial e validação das dimensões}

No passo seguinte procurou-se validar as dimensões previstas para a composição do indicador utilizando a análise fatorial. A hipótese básica dessa técnica é a de que em um conjunto de indicadores escolhidos ou testados existem dimensões latentes que se deseja obter ou identificar. Representa, portanto, um método analítico para determinar o número e a natureza de variáveis subjacentes a um grande número de variáveis e medidas. Como resultado, as variáveis apontadas no processo de rotação proporcionam a identificação e redução de um número de indicadores em fatores (dimensões) que consistem em uma aglomeração de dados semelhantes, facilitando a interpretação e a consequente associação ao referencial prático e científico (HAIR et al., 2005).

Para sua aplicação, algumas premissas devem ser satisfeitas, principalmente quanto à adequabilidade da técnica frente ao objetivo da pesquisa. Para Hair et al. (2005), as suposições críticas na análise fatorial são mais conceituais que estatísticas e desvios de normalidade, homocedasticidade e linearidade aplicam-se apenas no nível em que elas eventualmente diminuem as correlações observadas (HAIR et al, 2005, p. 98). Para eles, a normalidade é necessária quando um teste estatístico é aplicado para comprovar a significância dos fatores, mas isso raramente acontece. Os autores ainda argumentam que um pouco de multicolinearidade é desejável para a análise, pois o objetivo da técnica é identificar conjuntos de variáveis inter-relacionadas. Para rotação da matriz utilizou-se o método Varimax, que maximiza as altas correlações e minimiza as baixas (DANCEY; REIDY, 2006).

A partir dessas considerações, algumas medidas foram tomadas para a consecução da análise, efetuandose inicialmente um teste para medir adequação da amostra através do teste Kaiser-Meyer-Olkin - KMO, e do teste de esfericidade de Bartlett, utilizando-se como método de extração o de componentes principais. Para a formação dos fatores foram considerados aqueles com auto-valor (eigenvalue) maior que 1 (um). O teste de esfericidade de Bartlett fornece a probabilidade estatística da matriz de correlação apresentar correlações significativas entre algumas variáveis, e o KMO avalia em que medida as correlações parciais entre as variáveis são pequenas. A Tabela 2 apresenta os resultados dos testes.

Tabela 2. Medida de Adequação da Amostra e Teste de Esfericidade

\begin{tabular}{l|l|c}
\hline \multicolumn{3}{c}{ Medida de Adequação da Amostra Kaiser-Meyer-Olkin } \\
\hline \multirow{4}{*}{ Teste de Esfericidade Bartlett } & Aprox. Qui-Quadrado & 16862,984 \\
\cline { 2 - 3 } & Graus de liberdade & 595 \\
\cline { 2 - 3 } & Significância & 0,0000 \\
\hline
\end{tabular}

Fonte: Dados da pesquisa 
Pelo resultado, os testes mostram a adequabilidade da amostra para tratamento e realização da análise fatorial, pois com a aplicação do teste de esfericidade de Bartlett, buscam-se níveis de significância estatística < 0,05, e com o teste KMO, medidas que se aproximem da unidade (HAIR et al., 2005; BEZERRA, 2011).

Em seguida, analisou-se a composição de cada uma das dimensões formadas na primeira rotação, em um total de seis, com autovalor superior a 1. Porém, a composição desses fatores não suportava inteiramente as dimensões previstas, tomando-se como procedimento a exclusão passo a passo e individual de alguns desses indicadores, até o alcance de uma matriz composta por fatores perfeitamente identificáveis, e com suporte teórico em relação ao modelo inicial previsto. Esses procedimentos permitiram alcançar, após a rotação, um nível de variação explicada de $72,89 \%$, com quatro fatores identificáveis teoricamente, conforme se expõe na Tabela 3.

Tabela 3. Variância Explicada e Autovalores dos Componentes da Análise Fatorial

\begin{tabular}{|c|c|c|c|c|c|c|}
\hline \multirow[b]{2}{*}{ Componentes } & \multicolumn{3}{|c|}{ Autovalores iniciais } & \multicolumn{3}{|c|}{$\begin{array}{c}\text { Soma rotacionada das cargas ao } \\
\text { quadrado }\end{array}$} \\
\hline & Total & $\begin{array}{c}\% \text { da } \\
\text { Variância }\end{array}$ & Acumulada & Total & $\begin{array}{c}\% \mathrm{da} \\
\text { Variância }\end{array}$ & Acumulada \\
\hline 1 & 7,05 & 44,06 & 44,06 & 7,05 & 44,06 & 44,06 \\
\hline 2 & 2,06 & 12,85 & 56,91 & 2,06 & 12,85 & 56,91 \\
\hline 3 & 1,44 & 9,02 & 65,93 & 1,44 & 9,02 & 65,93 \\
\hline 4 & 1,12 & 6,97 & 72,90 & 1,12 & 6,97 & 72,90 \\
\hline
\end{tabular}

Fonte: Dados da pesquisa

A Tabela 4 demonstra a estrutura da matriz formada, e as respectivas cargas fatoriais.

Tabela 4. Componentes da Matriz Rotacionada

\begin{tabular}{|c|c|c|c|c|}
\hline & \multicolumn{4}{|c|}{ COMPONENTES } \\
\hline INDICADORES & FATOR-1 & FATOR-2 & FATOR-3 & FATOR-4 \\
\hline IComCor 1 & 0,863 & & & \\
\hline IComCor2 & 0,861 & & & \\
\hline IComCor3 & 0,846 & & & \\
\hline IComCor4 & 0,842 & & & \\
\hline IComp1 & & 0,709 & & \\
\hline IComp2 & & 0,802 & & \\
\hline IComp3 & & 0,717 & & \\
\hline IComp4 & & 0,795 & & \\
\hline IJusEti1 & & & 0,816 & \\
\hline IJusEti2 & & & 0,826 & \\
\hline IJusEti4 & & & 0,463 & \\
\hline IJusEti5 & & & 0,733 & \\
\hline ISocEcon 1 & & & & 0,439 \\
\hline ISocEcon2 & & & & 0,856 \\
\hline ISocEcon3 & & & & 0,882 \\
\hline ISocEcon4 & & & & 0,843 \\
\hline
\end{tabular}

Fonte: Dados da pesquisa

Sobre o conjunto de fatores resultantes, foram realizados os mesmos testes para adequação da amostra, estando, tanto o teste de esfericidade de Bartlett como o KMO, dentro dos padrões exigidos para a realização da 
análise, conforme Tabela 5.

Tabela 5. Medida de Adequação da Amostra e Teste de Esfericidade

\begin{tabular}{l|l|c}
\hline \multicolumn{2}{c|}{ Medida de Adequação da Amostra Kaiser-Meyer-Olkin } & 0,900 \\
\hline \multirow{3}{*}{ Teste de Esfericidade Bartlett } & Aprox. Qui-Quadrado & 4872,178 \\
\cline { 2 - 3 } & Graus de liberdade & 120 \\
\cline { 2 - 3 } & Significância & 0,0000 \\
\hline
\end{tabular}

Fonte: Dados da pesquisa

O primeiro fator formado na análise é conceituado como Fator de Compreensão sobre o Combate a Corrupção, que evidencia o nível de entendimento do cidadão sobre o seu papel e o do Estado no combate às práticas nocivas na gestão pública, tais como a corrupção, malversação de recursos, sonegação, e competição fiscal predatória. A composição do fator envolve os elementos apontados pela ESAF como nocivos ao sistema tributário, caracterizados pela prática de elisão e evasão fiscal, sonegação, fraudes fiscais, contrabando, descaminho, contração e pirataria (ESAF, CADERNO 3, 2009).

A corrupção tem sido apontada como um dos maiores entraves para o crescimento político e social dos países. Notadamente em relação aos países em desenvolvimento, em especial os da América Latina, esse fenômeno nocivo é caracterizado como causa e consequência de atrasos e descontinuidade de políticas reparadoras (RESENDE, 2002; ESAF, cad. 3, 2009; ESTEVEZ; ESPER, 2009; ESPER, 2010).

Estevez e Esper (2009), tratando da cidadania fiscal e das formas de relacionamento entre contribuintes e governo, salientam que a existência de corrupção, caracterizada pelo desvio de recursos públicos para fins particulares, acaba por repassar ao cidadão sentimento negativo, o de impunidade, que transmite um outro sentimento, o de quebra de um pacto social entre esse cidadão e o Estado. Esse sentimento por sua vez, pode diminuir o nível de compromisso do cidadão em relação ao cumprimento das suas obrigações sociais. Esses argumentos apenas reforçam o sentimento coletivo de buscar meios para acabar com a corrupção, caracterizada no Brasil não só pelo comportamento dos agentes públicos no exercício das suas funções, mas também pelas práticas apontadas pela ESAF.

O segundo fator é conceituado como Fator de Compreensão do Papel do Estado, que evidencia o nível de entendimento do cidadão sobre o papel do Estado, seus mecanismos de financiamento e o desempenho das funções públicas. Considera ainda o entendimento sobre a restauração da legitimidade do papel do Estado, pela compreensão e interpretação adequada das suas leis e de seus atos moralmente condicionados.

Consta no preâmbulo da Constituição Federal que a instituição do Estado Brasileiro, é [...]destinado a assegurar o exercício dos direitos sociais e individuais, a liberdade, a segurança, o bem-estar, o desenvolvimento, a igualdade e a justiça como valores supremos de uma sociedade fraterna, pluralista e sem preconceitos, fundada na harmonia social e comprometida, na ordem interna e internacional, com a solução pacífica das controvérsias[...] (CF, 1988).

Essa ideia retrata uma espécie de pacto social mantido entre os cidadãos e o próprio Estado, tendo este último, as obrigações conceituadas nas variáveis que compõem o fator. Se cumpridos, esses deveres acabam por reforçar o acordo social, impulsionando o cidadão a cumprir suas obrigações. Do contrário, tem-se quebrado o pacto, prejudicando o crescimento político, financeiro e social do país. O que se evidencia é um entendimento coletivo dessas obrigações por parte dos pesquisados, que demonstram conhecer não só suas obrigações, mas as de competência do Estado instituídas para regulá-los.

O Terceiro fator indica o entendimento sobre o papel público na promoção da justiça fiscal e da ética distributiva. $\mathrm{O}$ fator se coaduna com os princípios constitucionais e de ordem tributária destacados nos artigos $5^{\circ}$ e $150^{\circ}$ da Constituição Federal, quanto à legalidade (art. $150^{\circ}$, I), anterioridade da lei (art. $150^{\circ}$, III, b e c), irretroatividade (art. 150 ${ }^{\circ}$ III), isonomia (caput do art. 5o), da uniformidade da tributação (art. 151, I), da capacidade contributiva (art. 145, § $1^{\circ}$ ), e do não confisco (art. 150, IV).

Pelo contexto observado, evidencia-se que o conhecimento desses princípios independe de orientação formal, destacada pela realização de treinamentos específicos, por exemplo o curso de disseminadores da ESAF, pois quase $50 \%$ dos pesquisados, apesar de não terem realizado o curso, demonstram adequado entendimento 
sobre as obrigações mútuas de cidadãos e do Estado.

Essa percepção reforça os conceitos de ética distributiva e justiça fiscal apresentados no modelo conceitual adotado, que se traduzem na busca por Estado justo, de bem-estar social, resultante também da adequada administração de recursos, com equidade, progressividade, neutralidade e simplicidade (CF ART. $3^{\circ}$. DA CF; ESAF - CAD. 2 DO PNEF; MATIAS-PEREIRA, 2009).

O quarto fator é conceituado como Fator de Entendimento da Função Socioeconômica do Tributo, que indica o entendimento por parte do cidadão sobre o que representa a função socioeconômica do tributo e dos procedimentos fiscais de combate às desigualdades sociais.

A função socioeconômica do tributo materializa-se no cumprimento da função social do Estado em promover o bem comum, a igualdade e a justiça, por meio dos desenvolvimentos social e econômico (ESAFPNEF, Cad., 2009). Isso significa que o Estado deve garantir igualdade de condições, baseados em princípios que corrijam as eventuais falhas que impeçam esse desenvolvimento.

Para a ESAF, o financiamento do Estado através dos tributos deve permitir o cumprimento de suas três funções essenciais: (a) garantir os recursos necessários ao Estado para realização de seus fins; (b) ser instrumento de distribuição de renda e indutor do desenvolvimento social; e (c) contribuir para minimizar as diferenças regionais. Isso só é possível, segundo a gestora do PNEF, com a participação da sociedade (ESAF/PNEF - cad. 3, 2009).

Pelo que se observa nos resultados apresentados, é possível afirmar que os elementos que fundamentam a educação fiscal permitem mensurá-la em forma de indicador multidimensional, com pelos menos quatros dimensões observáveis, possibilitando no contexto observado, estabelecer uma escala de medição do nível de formação educacional fiscal dos cidadãos. Esses achados, a partir dos conceitos utilizados, podem ajudar a estabelecer um modelo teórico que fundamente um construto sobre a formação fiscal do cidadão.

\section{CONSIDERAÇÕES FINAIS}

Pode-se sustentar que o presente estudo - apesar das limitações inerentes a sua consumação, como a composição do instrumento de pesquisa, por considerar dimensões específicas, e o próprio comprometimento do pesquisado - atende ao proposto na literatura sobre a educação fiscal quanto a sua disseminação e a busca de instrumentos que verificam seu impacto sobre as pessoas e a sociedade, pois confirma a possibilidade de mensuração por múltiplos componentes, definidos a partir das bases do PNEF e dos princípios constitucionais.

Os resultados evidenciam que a educação fiscal e seus fundamentos são entendidos pela população, que reconhecem a sua importância, pressupondo ainda uma contribuição ao estado da arte da pesquisa na medida em que fomenta e dissemina a temática da educação fiscal no contexto acadêmico em nível de graduação e pósgraduação e abre campo para estudos que objetivem revalidar os achados.

Como elementos motivadores à realização de novas pesquisas recomenda-se elaborar pesquisas e estudos sobre o PNEF e suas bases, a partir de uma avaliação pedagógica do programa, com diretrizes didáticas específicas para grupos de usuários com diferentes níveis educacionais e classes sociais, bem como sua replicação de forma segregada, seja por região geográfica, classe social ou níveis educacionais.

\section{REFERÊNCIAS}

ÁREA DE SOCIOLOGÍA TRIBUTARIA (2001): Opiniones y actitudes fiscales de los españoles, Documentos del Instituto de Estudios Fiscales, Madrid.

(2004): Opiniones y actitudes fiscales de los españoles en 2005, Documentos del Instituto de Estudios Fiscales n. ${ }^{\circ} 11 / 05$. p. 1-77, Madrid.

(2005): Opiniones y actitudes fiscales de los españoles en 2006, Documentos del Instituto de Estudios Fiscales n. ${ }^{\circ}$ 10/06. p. 1-84, Madrid.

(2006): Opiniones y actitudes fiscales de los españoles en 2006, Documentos del Instituto de Estudios 
Fiscales n. ${ }^{\circ}$ 21/07. p. 1-97, Madrid.

(2007): Opiniones y actitudes fiscales de los españoles en 2007, Documentos del Instituto de Estudios Fiscales n. ${ }^{\circ} 15 / 08$. p. 1-91, Madrid.

(2008): Opiniones y actitudes fiscales de los españoles en 2008, Documentos del Instituto de Estudios Fiscales n. ${ }^{\circ}$ 15/09. p. 1-94, Madrid.

BEZERRA, F. A. Análise Fatorial. In: CORRAR, Luiz J.;PAULO, Edilson; DIAS FILHO, José Maria. Análise multivariada para os cursos de administração, ciências contábeis e economia. $1^{\mathrm{a}}$ ed. 3 . Impressão. São Paulo: Atlas, 2011. p. -130.

BORGES, E.F. Educação Fiscal e Eficiência pública: um estudo das suas relações a partir da gestão de recursos municipais. Natal, 2011.Tese (Doutorado em Ciências Contábeis). Programa de Doutorado Multiinstitucional e Inter-regional de Pós-graduação em Ciências Contábeis (UnB/UFPB/UFRN)

BORGES, E. F; NASCIMENTO, V. C; COSTA, F. M. de S.; COSTA, G. M. Uma visão exploratória da educação fiscal presente na formação do graduando em ciências contábeis da Universidade Federal do Rio Grande do Norte. Revista Brasileira de Contabilidade, Brasília, v. 1, no. 174, p. 69-83, nov/dez, 2008.

BRASIL. Constituição Federal (1988). Constituição da República Federativa do Brasil: promulgada em 5 de outubro de 1988. Brasília: Senado Federal, Subsecretaria de Edições Técnicas, 2000.

Ministério da Fazenda; Ministério da Educação. Escola de Administração Fazendária. Programa Nacional de Educação Fiscal: Educação fiscal no contexto social (Série Educação Fiscal. Cadernos). Brasília, 2004. Disponível em: http://www.esaf.fazenda.gov.br/parcerias/educacao-fiscal/caderno/caderno_1.pdf Acesso em: 30 maio 2009.

Programa Nacional de Educação Fiscal. Por que a nossa sociedade precisa abraçar este programa. Disponível em: www8.pr.gov.br/portals/portal/educacaofiscal/ppt/ educacao_fiscal-tributo_e_justica_social. ppt Acesso em: 30 maio 2009.

Receita Federal. Educação fiscal: uma prática possível e necessária. Disponível em: <http://www.receita. fazenda.gov.br/EducaFiscal/default.htm> . Acesso em: 30 maio 2009.

Superintendência da Receita Federal. Programa Nacional de Educação Fiscal. O papel da Justiça Fiscal em um país de contrastes. Minas Gerais. Disponível em: $<$ http://www.esaf.fazenda.gov.br/parcerias/ educacao-fiscal/programa.pdf>. Acesso em: 30 maio 2009.

BUFFON, Marciano. Tributação e dignidade humana: entre os direitos e deveres fundamentais. Porto Alegre: Livraria do Advogado, 2009.

CARTAXO, Maria de Fátima Pessoa de Mello. EDUCAÇÃO FISCAL: uma prática possível e necessária, 2004. Disponível em:<www.esaf.fazenda.gov.br/parceria/educação-fiscal>. Acesso em: 25 mar. 2010.

CERVO, Amado Luis; BERVIAN, Pedro Alcino; DA SILVA, Roberto. Metodologia científica. 6. ed. São Paulo: Persoan Prentice Hall, 2007.

CORRALES, M.Y. C.; GARCÍA, W.J.D. : “La cultura tributaria municipal. Diagnóstico en La parroquia El Valle del municipio boliariano del distrito capital" en Observatorio de la Economía Latinoamericana $\mathrm{N}^{\mathrm{o}} 81$, junio 2007. Dipsonível em:< http://www.eumed.net/cursecon/ecolat/ve/>. Acesso em: 13 mai. 2011.

CRONBACH, L. Coefficient alpha and the internal structure of tests. Psychometrika, 16, 297-37, 1951.

DANCEY, C. P.; REIDY, j. Estatística sem matemática para psicologia. Tradução Lori Viali. - Porto Alegre: Artmed, 2006.

DEVELLIS, R.F. (1991). Scale Development: theory and applications (Applied Social Research Methods Series, Vol. 26). Newbury Park: Sage.

ESPER, S. C.. La relación entre el pacto social y el sistema tributario: la

subjetividad fiscal de la ciudadanía argentina. Congreso Argentino de Gobernancia en las OrganizacionesUniversidad del CEMA 2010. Disponível em: $<$ http://www.ucema.edu.ar/sites/default/ files/download/cegopp/Estevez.pdf>. Acesso em: 19 jul. 2011.

ESTÉVEZ, Alejandro M. La ciudadanía fiscal: un marco teórico. Congreso Argentino de Gobernancia en las OrganizacionesUniversidad del CEMA 2010. Disponível em: < http://www.ucema.edu.ar/sites/default/ 
files/download/cegopp/Estevez.pdf $>$ Acesso em: 19 jul. 2011.

ESTÉVEZ, Alejandro M; ESPER, Suzana C. Ciudadanía fiscal y nuevas formas de relación entre contribuyentes y administración tributaria. Administración Federal de Impuestos. Revista de Ciencias Económicas y Estadisticas-SaberEs. No 1 (2009). 63-74. Sección Artículos. Disponível em: <http://www.fcecon.unr.edu.ar/ revista/index.php/revista/article/view/5/37>Acesso em: 19 jul. 2011.

FERNÁNDEZ, J.M; RUIZ, M.A.G, Un paso más en la colaboración tributaria a través de la formación: el programa Fiscalis de la Unión Europea. Instituto de Estudos Fiscales. Doc. 27/02. Madrid. Espanha, 2002.

FREIRE, Paulo. Pedagogia do oprimido. 44. ed. Rio de Janeiro: Paz e Terra, 2005.

GARCIA, M. L. V. Los impuestos, instrumentos de solidaridad El Programa de Educación Cívico-Tributaria de la Agencia Tributaria española. Instituto de Estudos Fiscales. Madrid. Espanha, 2008.

GARCIA, S.A; MOLINA, P.M.H. La ética en el diseño y aplicación de los sistemas tributarios. Instituto de Estudos Fiscales. Doc. 16/04. Madrid. Espanha, 2004.

GARCÍA, G. A.; ESCOBAR, L. de P. La conciencia fiscal y el fraude fiscal. Factores que influyen en La tolerancia ante el fraude. Universidad Complutense de Madrid. Disponível em: < $\underline{\text { http://eprints.ucm.es/6859/1/0702. }}$ pdf>. Acesso em: 16 set. 2011.

GIL, Antonio Carlos. Métodos e técnicas de pesquisa social. 5. ed. São Paulo: Atlas, 2006.

GIARRIZZO, V.; SIVORI, J. S. La inconsistencia de la moral tributaria. El caso de los moralistas evasores. Revista de la Facultad de Ciencias Económicas y Empresariales, Universidad de León . Num. 10 Pecvnia, 10 (2010), pp. 95-124. Disponível em: < http://www.erevistas.csic.es/ficha_articulo.php?url=oai_ revista538:143\&oai_iden=oai_revista538>. Acesso em: 25 set. 2011.

GRZYBOVSKI, Denise; HAHN, Tatiana. Educação fiscal: premissa para melhor percepção da questão tributária. Revista de Administração Pública (RAP) Rio de Janeiro 40(5): 841-64, Set./Out, 2006

HAIR, J. F.; ANDERSON, R.E.; TATHAM, R.L. e BLACK, W.C. Multivariate data analysis. 5a. New Jersey: Prentice Hall, 2005.

KENNA, M. Educación Tributaria y Desarrollo Profesional en Las Escuelas Arquidiocesanas. Revista Comercium et Tributum. Volumen V Edición No. 1 - Enero, 2011. Disponível em: <http://publicaciones. urbe.edu/index.php/comercium/article/viewArticle/968>. Acesso em: 17 de ago. 2011.

KINNEY, R.A.M. La justicia fiscal em el marco de la teoría de la justicia como equidad de John Rawls. La tributación ¿carga, obligación o donación?Revista internacional de éticas aplicadas (DILEMATA). Ano 2. N. 4 septiembre 2010. Disponível em: <http://www.dilemata.net/revista/index.php/dilemata/article/view/57>. Acesso 17 ago. 2011.

LIMA, A. S. S. Uma contribuição ao marketing social e a educação fiscal no Brasil: Análise por meio de casos múltiplos. Rio de Janeiro, 2008. Tese. Departamento de Dirección de Empresas y Sociología. Universidad de Extremadura. Badajoz. Espanha.

LOBO, M. L. D; PARAMIO, M. F.; GARCIA-VERDUGO, A. M.; MUÑIO, C.R.; GARCIA, M.L.V. La Educaion Fiscal en España. Instituto de Estudos Fiscales. Doc. 29/05. Madrid. Espanha, 2005.

MARCONI, Maria de Andrade; LAKATOS, Eva Maria. Metodologia científica. 5 ed. São Paulo: Atlas, 2007.

MAROCO, J.; MARQUES, T.G. Qual a fiabilidade do alfa de Cronbach? Questões antigas e soluções modernas?. Laboratório de Psicologia, I.S.P.A.4(1): 65-90, 2006.

MATIAS-PEREIRA, José. Finanças Públicas: A política orçamentária no Brasil. 5 ed. São Paulo: Atlas, 2009.

MANTOVANI, D. M. N.; VIANA, A. B. N. Atitudes dos alunos de administração com relação à estatística: um estudo comparativo entre antes e depois de uma disciplina de graduaçãoRevista de Gestão USP, São Paulo, v. 15, n. 2, p. 35-52, 42 abril/junho, 2008.

MUNOZ, C. P. Impuestos y Justicia Distributiva: Una Evaluación de La Propuesta de Justicia Impositiva de Murphy y Nagel*. Rev. Urug. Cienc. Polit. [online]. 2007, vol.16, n.1, pp. 201-221. ISSN 0797-9789.

NEVES, Eliomar Pires. Educação Fiscal e Responsabilidade Social: Um estudo de caso na Delegacia da Receita Federal em Feira de Santana. Bahia, 2008. Dissertação (Mestrado Profissional Multidisciplinar em Desenvolvimento Humano e Responsabilidade Social) - Centro de Pós-Graduação e Pesquisa Visconde de 
Cairu. Faculdade Visconde de Cairu.

Nunnally, J. C.. Psychometric theory. New York: McGraw-Hill Inc, 1978.

PEREIRA, Arlindo Amorim. Programa de Educação Tributária da Bahia: A Visão dos atores envolvidos no seu grupo e a implementação do programa. Bahia, 2005. Dissertação (Mestrado em Administração) - Núcleo de Pós-Graduação em Administração. Escola de Administração da Universidade Federal da Bahia.

PERTUZATTI, Elizandra; MERLO, Roberto Aurélio. O programa de educação fiscal do Estado de Santa Catarina: Uma reflexão sobre o papel do contador. Revista Universo contábil. Vol. 1, no 3 p. 48-62, set/dez, 2005.

RESENDE, Flavio da Cunha. O dilema do controle e a falha seqüencial nas reformas gerenciais. Revista do Serviço Público. N3 p. 50-74, jul/set, 2002.

SAINZ DE BUJANDA, F. (1967): Teoría de la educación tributaria. Hacienda y Derecho. Instituto de Estudios Políticos. V. IX, no. 24 p. 343-500, Madrid, 1962.

SAVIANI, Dermeval. A Filosofia da Educação e o problema da inovação em educação. In: GARCIA, Walter E. (Coord.). Inovação educacional no Brasil. Problemas e perspectivas. São Paulo: Cortez, 1980. p. 15-29.

SAVIANI, Dermeval. Educação: do senso comum à consciência filosófica. São Paulo: Cortez, 1980.

Pedagogia Histórico-Crítica: primeiras aproximações. $10^{\mathrm{a}} \mathrm{ed}$. rev. Campinas. São Paulo: Editores Associados, 2008 (coleção educação contemporânea).

SHOLZ, Rejane Teresinha. O Princípio da informação no Direito Tributário. Curitiba, 2005, 192 p. Dissertação (Mestrado em Direto) Centro de Ciências Jurídicas e Sociais. Pontifícia Universidade Católica do Paraná $\mathrm{PUC} / \mathrm{PR}$

TÁPIA, M.; GAONA, W. TAMBUCO, P. La educación tributaria como medida para incrementar la recaudación fiscal en Ecuador. 2009 .Disponível em http://www.dspace.espol.edu.ec/handle/123456789/4774 . Acesso em: 14 de abr de 2011.

YUBERO, F.D.; LOBO, M. L. D; GARCIA, M. L. V. Los impuestos, instrumentos de solidaridad EI Programa de Educación Cívico-Tributaria de la Agencia Tributaria española. Instituto de Estudos Fiscales. Madrid. Espanha, 2008.

YUBERO, F.D.(ORG.); LOBO; M. L. D.; VERDUGO, A. M. G.; PARAMIO, M. F.; MUÑIO, C. R.; GARCIA, M.L.V; ANEL,J. L.; CONESCA, F.M.; RAMOS, J.J.M; ZUAZU, M. G. R. La experiencia educativa de la Administración Tributaria Española. Instituto de Estudos Fiscales, 13/09. Madrid. Espanha, 2009.

ZEA, M.C. "Propuesta para crear una unidad movil de capacitación como herramienta para el fortalecimiento De la cultura tributaria en guatemala". Maestría en administración de recursos humanos. Universidad de San Carlos de Guatemala Facultad de Ciencias Econômicas Escuela de Estudios de Postgrado, p. 109, 2011. 